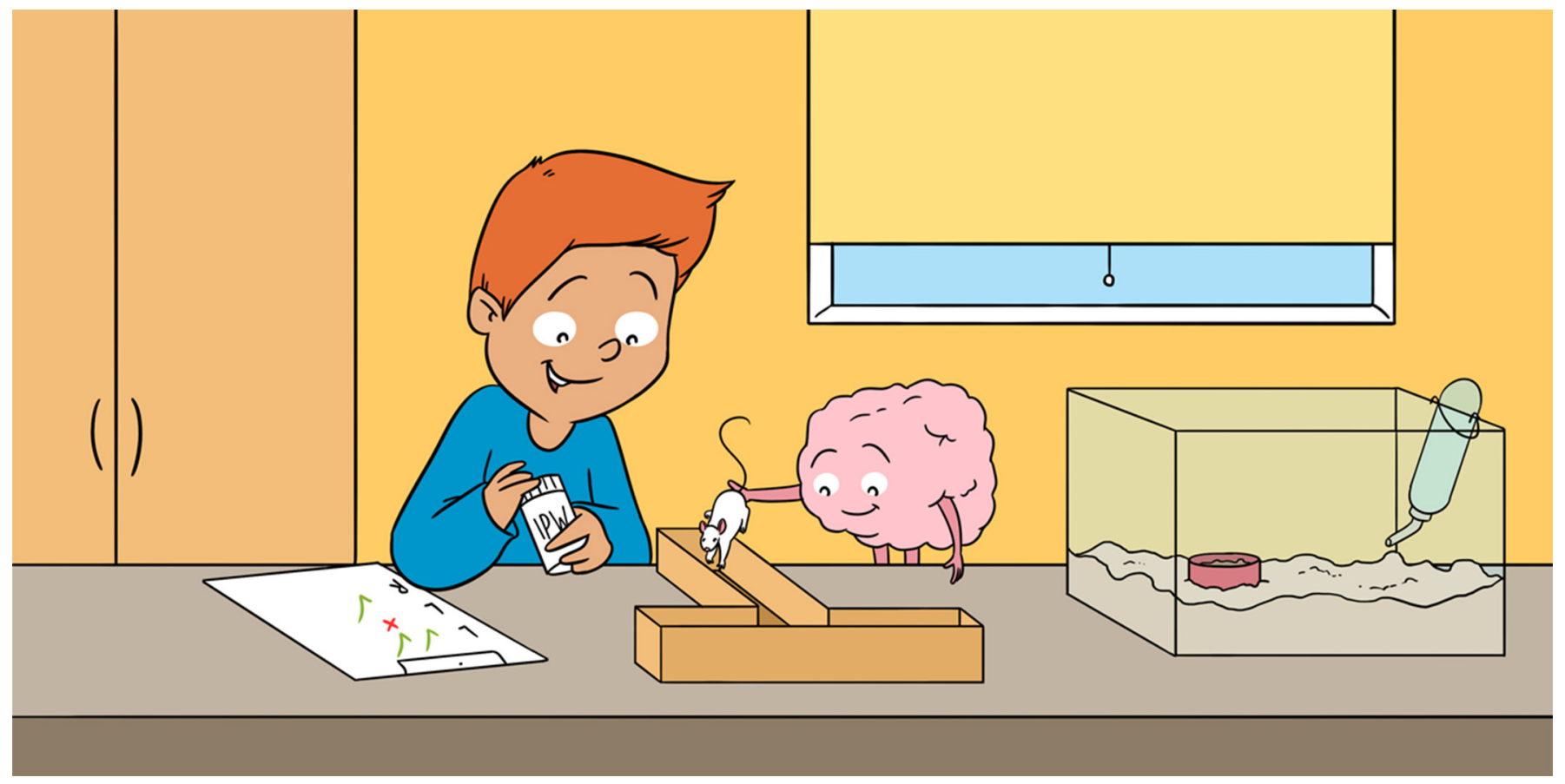

\title{
AS WE AGE, THE "SHIELD" THAT PROTECTS THE BRAIN GETS LEAKY
}

Jessica M. Lin ${ }^{1,2}$, Vladimir V. Senatorov Jr. ${ }^{1,2}$ and Daniela Kaufer ${ }^{1,2,3^{*}}$

${ }^{1}$ Helen Wills Neuroscience Institute, University of California, Berkeley, Berkeley, CA, United States

${ }^{2}$ Department of Integrative Biology, University of California, Berkeley, Berkeley, CA, United States

${ }^{3}$ Canadian Institute for Advanced Research, Toronto, ON, Canada

YOUNG REVIEWERS:

UC IRVINE

BRAIN

EXPLORER

ACADEMY

AGES: 7-14

\section{BLOOD-BRAIN}

BARRIER (BBB)

A membrane that controls which

molecules can cross between the

bloodstream and

the brain.
You might have noticed that as people grow older, they are more likely to suffer from memory loss, and they may learn things slower than you can. What causes these changes to our brain function? Our research has found that as we age, the membrane that protects our brain called the blood-brain barrier (BBB), becomes "leaky," allowing unwanted proteins from the bloodstream to enter the brain. In this article, we explain how a leaky BBB can lead to damaged brain function. Moreover, we discuss the possibility of finding a cure to prevent this leakiness.

\section{WHAT IS THE BLOOD BRAIN BARRIER AND WHAT HAPPENS WHEN THIS SHIELD BREAKS DOWN?}

Our brains are protected by a shield known as the blood-brain barrier (BBB). It gets its name because, in a healthy brain, components of the blood are excluded from the brain tissue by a barrier made 
HIPPOCAMPUS

A brain region important for learning and memory. Hippocampus means "seahorse" in Greek, referring to its curved shape.

\section{ALBUMIN}

A blood protein normally absent from the brain of healthy individuals

\section{DEMENTIA}

A term used to describe symptoms, such as impaired memory, learning, and speech. up of different cells and other factors, which creates a division between the circulatory system and the brain. We call this barrier semi-permeable, meaning that only certain molecules important for the brain's functioning are allowed to cross. As we get older, this barrier becomes "leaky," allowing forbidden molecules to enter.

When we are young, the BBB is intact. During middle age, we find the first evidence of wear-and-tear. A small percentage of people begin to have blood proteins in a part of the brain called the hippocampus [1]. Hippocampus means seahorse in Greek, representing this brain area's curved shape. The hippocampus is one of the most important and adaptable brain regions. When you experience something new, your hippocampus responds by forming novel connections between brain cells called neurons, and sometimes removing old connections as well. This making and removing of connections is called plasticity and through this plasticity, the hippocampus plays an important role in learning and memory. However, researchers think this plasticity also makes the hippocampus especially vulnerable to aging [2], which is dangerous because damage to the hippocampus can reduce our ability to learn new things or recall things we learned before.

Around age 65 or so, many people have some amount of blood proteins in their brains, increasing their risk for diseases that affect the brain [1]. The presence of blood proteins in the brain happens in many people but is not well-understood, so we sought to investigate how and why it happens (Figure 1). There is not much existing research on how the BBB breaks down in old age. Therefore, we looked for inspiration from a different system that has been well-studied: traumatic brain injury (TBI). TBI happens when a physical trauma happens to the head, damaging the skull and brain. We thought that perhaps natural aging has a similar effect on the BBB as TBI, except that the damage caused by aging happens more slowly, over many years, instead of in one fell swoop. TBI and aging may seem very different, but they are more similar than you think. In the case of TBI, it is easy to conclude that the BBB suffers harm from the physical impact, the way a bicycle helmet gets dented when you fall and hit your head. However, BBB damage in TBI also occurs from swelling around the injury site, or from other bodily reactions triggered by the injury [3]. Once a TBI damages the BBB, a blood protein called albumin that is normally excluded from the brain leaks in.

Why is it bad if albumin gets into the brain? Well, albumin can cause certain cells in the brain to receive extra signals through a molecule on their surface called the TGF- $\beta$ receptor. We think this extra signaling caused by albumin happens both after TBI and during aging [4]. Approximately $10-40 \%$ of patients who have suffered TBIs develop epilepsy later in life [5], and diseases, such as dementia or epilepsy affect the elderly much more than the young, which makes us think that signaling through the TGF- $\beta$ receptor also plays a role in age-related BBB disruption. 
Figure 1

An illustration of the blood-brain barrier in an aging brain. Here, albumin molecules (shown in green) leak from a broken blood vessel and bind to the TGF- $\beta$ receptor found on astrocytes (shown in white). Notice the astrocytes wrap their "arms" around the blood vessel to assist in the regulation and maintenance of the blood-brain barrier. Artist: Karli Haugen.

\section{ASTROCYTE}

A star-shaped cell that forms part of the blood-brain barrier ("Astro" means star in Latin).

\section{GENETIC} KNOCKOUT

A technique that removes a particular gene from an individual's DNA.

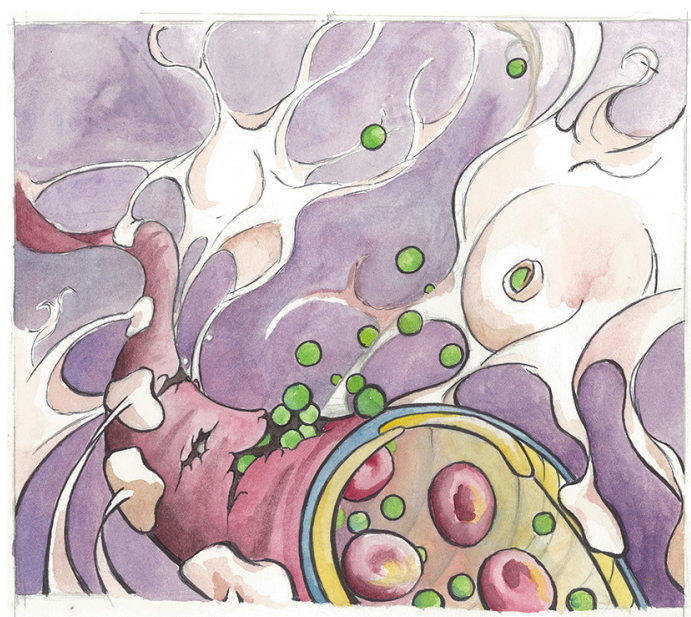

Figure 1

So how exactly does this signaling through the TGF- $\beta$ receptor work? We are interested in a particular type of cell in the brain called an astrocyte, which has lots of TGF- $\beta$ receptors. Thanks to their unique, star-like shape (astrum means star in Latin), astrocytes are able to stretch and wrap their "arms" around blood vessels, making these cells an important component of the BBB (Figure 1). Among their various roles, astrocytes regulate blood flow to neurons and assist in choosing which molecules can cross from the blood into the brain [6]. They also play a key role in injury response following BBB damage. When the TGF- $\beta$ receptor on astrocytes is activated, the astrocytes release chemical signals that cause inflammation in the surrounding environment (Figure 2) [7]. You may have noticed that when you sprain your ankle, the ankle tissue becomes swollen, or when you get a fever, your muscles ache and your forehead becomes hot. These are just some examples of your body's inflammatory responses. In the correct context, these reactions help the body to heal. However, it is difficult to go about daily life if your ankle swells so much you cannot walk, and it can be dangerous to have a fever that runs too high. Similarly, long-term or unnecessary inflammation caused by astrocytes can be disruptive to the brain's normal functioning.

\section{WHAT DO SWIMMING MICE HAVE TO DO WITH DEMENTIA?}

To test a possible treatment for the damaging effects of the leaky BBB we had to modify the genes of some mice. Our goal was to "knock out" the inflammation-causing TGF- $\beta$ receptor, in a process known as genetic knockout. In other words, we used biotechnology to delete these receptors from the mouse's DNA. DNA is the long chemical ribbon that contains our genetic code, information for traits, such as eye color, height, and even our risk for certain diseases. Modern biotechnology allows us to use molecular scissors to snip out any 
Figure 2

When albumin enters the brain and binds to the TGF- $\beta$ receptor on astrocytes, an inflammatory response spreads throughout the brain, eventually reaching the neurons Neurons can become damaged if the inflammatory response lasts too long.
MORRIS WATER

MAZE (MWM)

A test of learning ability. Mice are placed in a giant pool of water and must find a hidden platform.

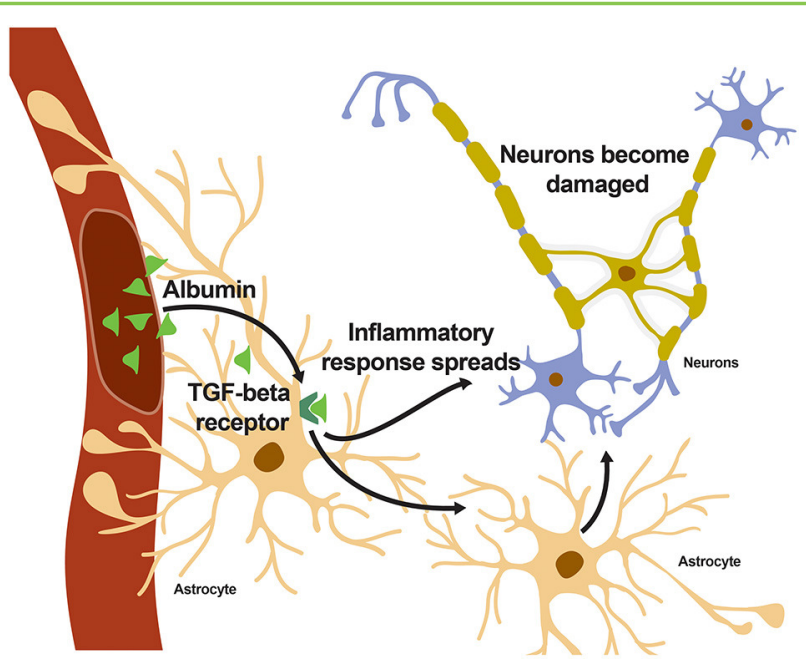

Figure 2

part of the DNA. In this case, we could use this technology to cut away the gene that codes for the TGF- $\beta$ receptor and paste the rest of the DNA back together into a continuous ribbon again. Imagine how incredible that is, given that DNA is 40,000 times thinner than the width of a piece of paper! Then, with our genetically modified mouse, we could determine how reducing the inflammation response affects brain function in old age.

One of the important tests we used on our genetically modified mice is called the Morris water maze (MWM). In this task, mice are placed in a giant pool with a hidden platform (Figure 3). Mice are naturally good swimmers, but they hate getting wet, so they will try to find the platform to stay dry. We can assess how quickly they learn where the platform is, and whether or not they remember its location some days later, and this tells us how well their brains are functioning. To make things trickier, we mix white paint into the water so the mice cannot see exactly where the platform is. Instead, they must use four colorful shapes on the walls of the pool to memorize the platform's location. If we were to remove the street sign from your street, you could probably still recognize where you live based on landmarks you see every day, such as the doghouse in your neighbor's front yard, or the maple tree on your street corner. After multiple days of being shown where the platform is, a mouse with a healthy brain can find the hidden platform based on the same principle. We call this a test of spatial reasoning. If you remember, BBB breakdown causes the most damage to the brain region called the hippocampus. The hippocampus happens to be in charge of spatial reasoning, as well as learning ability-two cognitive abilities that decline with aging.

We first tried the MWM on a group of old mice with the TGF- $\beta$ receptor knocked out, and compared their performance with a control group of old control mice that did not have the gene knocked out. If our hypothesis was correct, the knockout mice should have learned the 
Figure 3

A mouse practices the Morris water maze, a test for spatial reasoning and memory. White paint is mixed into the pool so the mouse cannot easily see the platform location. Instead, the mouse must rely on the colored shapes on the wall of the pool to help it memorize where the platform is hidden. In the right panel, observe the mouse's learning over the course of 3 days. Artist: Karli Haugen.

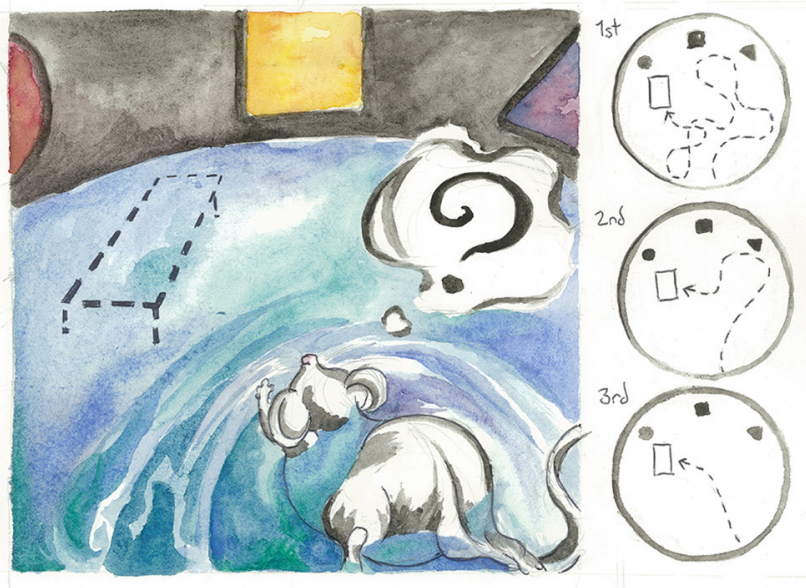

Figure 3

location of the hidden platform faster than the control mice and should have been able to consistently find the platform in the days following. However, it turned out both groups of mice were too old to swim properly, so they were unable to complete the test [1]! Science can be tricky like that. Sometimes, there are unexpected complications and scientists need to think of new ways around these obstacles.

Rather than using old mice that could not swim, we repeated the experiment with younger mice. Like before, we divided the mice into two conditions $-a$ knockout group that had no TGF- $\beta$ receptors, and a control group. However, young mice have virtually no albumin in their brains. This meant we had to create an artificial way to mimic this aspect of aging. To do this, we implanted a tiny pump that pumped albumin into the brains of both groups of mice for a week. This time, when we repeated the MWM with our younger mice, our results were significant. We discovered that pumping albumin into the brains of young control mice caused symptoms of aging-memory loss and abnormal brain wave activity. On the other hand, the young knockout group, whose brains had no TGF- $\beta$ receptors for albumin to bind to, learned the location of the hidden platform relatively quickly. These results suggested that blocking TGF- $\beta$ signaling could reverse the damage done to the brain by albumin [1].

\section{A POSSIBLE TREATMENT FOR BBB BREAKDOWN}

Unfortunately, we cannot (at least not yet) genetically alter humans to knock out their TGF- $\beta$ receptors, as doing so would be both unethical and difficult. Instead, we strove to create a drug that could achieve the same effect. We named this drug IPW. IPW is a small molecule that binds to the TGF- $\beta$ receptor and prevents it from being activated. You can think of IPW as a goalie in a soccer game. When the goalie is absent, players can kick the soccer ball into the net; likewise, in the 
Figure 4

A mouse explores the T-maze. Old mice receiving IPW treatment tended to explore a different arm of the $T$ each time they were placed in the maze, while control mice who received no treatment often forgot which arm they already explored and chose the same arm over and over again. Artist: Karli Haugen.

\section{T-MAZE}

A test for memory. Because mice like to explore, mice pass the test if they alternate between exploring the left and right arms.

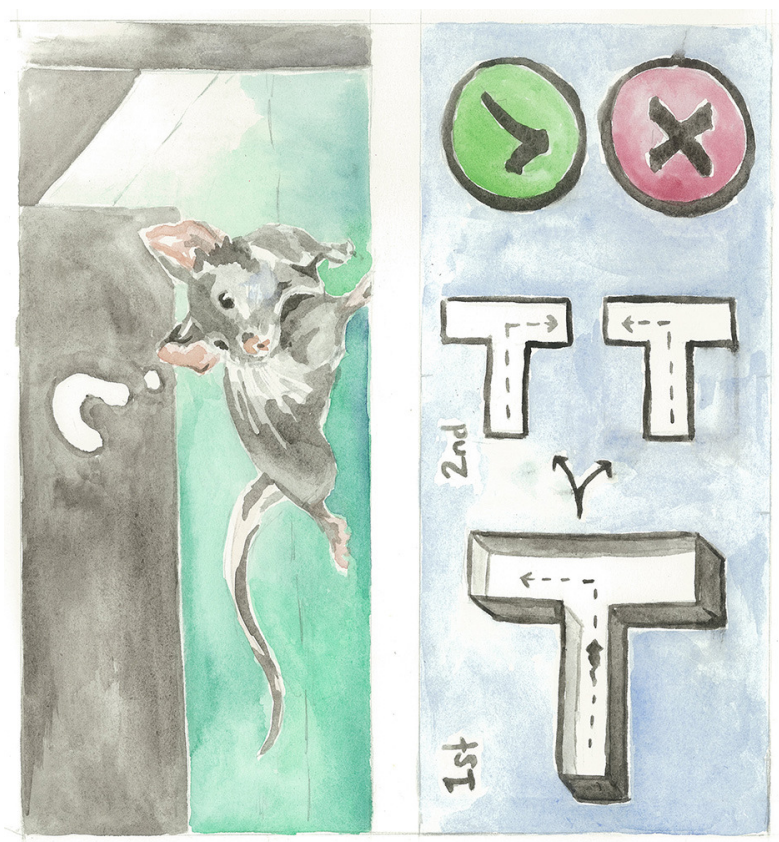

Figure 4

absence of IPW, albumin can bind to the TGF- $\beta$ receptor. However, when the goalie blocks the way, the ball cannot enter the goal. In the same way, IPW blocks albumin from binding to its target, preventing inflammatory signaling from occurring.

To test IPW's effectiveness, we used another test for mice called the T-maze. As the name suggests, mice are placed in a maze shaped like a $\mathrm{T}$. Wandering down the vertical projection of the $\mathrm{T}$, the mice have a choice of exploring either the left arm of the $\mathrm{T}$ or the right arm (Figure 4). Mice are naturally curious animals, so healthy mice will alternate their visits between the left and right arms to maximize their exploration. Older mice suffering from age-related memory loss, on the other hand, tend to forget which side they have already explored, so they will sometimes explore the same arm many times in a row. Just like the MWM, the T-maze tests both memory and spatial reasoning, making it a good assessment for hippocampal performance. Old mice treated with IPW performed better in the T-maze than their untreated counterparts [1], which reveals that blocking TGF- $\beta$ receptor activation restores the mouse's memory, and allows them to solve the maze like a young mouse.

\section{CONCLUSION}

Where do we go from here? In our next steps, we strive to go forward and bridge the gap between mice and humans, a process that can be slow and complex. Our oral or injectable forms of IPW inhibit TGF- $\beta$ receptors throughout the body, yet we have found that knocking out TGF- $\beta$ receptors in astrocytes alone was enough to achieve the same 
effect. There are other unanswered questions, such as whether IPW has unwanted side effects, and how we can use a brain scan to detect BBB leakiness during a routine physical check-up. We have been lucky to collaborate with doctors, chemists, and engineers as we continue to develop a solution. The question of how to slow down-or even reverse-aging is too big of a question to answer through just one type of research alone.

\section{ORIGINAL SOURCE ARTICLE}

Senatorov, V. V., Friedman, A. R., Milikovsky, D. Z., Ofer, J., Saar-Ashkenazy, R., Charbash, A., et al. 2019. Blood-brain barrier dysfunction in aging induces hyperactivation of TGF $\beta$ signaling and chronic yet reversible neural dysfunction. Sci. Transl. Med. 11:eaaw8283. doi: 10.1126/scitranslmed.aaw8283

\section{REFERENCES}

1. Senatorov, V. V., Friedman, A. R., Milikovsky, D. Z., Ofer, J., Saar-Ashkenazy, R., Charbash, A., et al. 2019. Blood-brain barrier dysfunction in aging induces hyperactivation of TGF $\beta$ signaling and chronic yet reversible neural dysfunction. Sci. Transl. Med. 11:eaaw8283. doi: 10.1126/scitranslmed.aaw8283

2. Bartsch, T., and Wulff, P. 2015. The hippocampus in aging and disease: from plasticity to vulnerability. Neuroscience 309:1-16. doi: 10.1016/j.neuroscience.2015.07.084

3. Price, L., Wilson, C., and Grant, G. 2016. "Blood-brain barrier pathophysiology following traumatic brain injury," in Translational Research in Traumatic Brain Injury, Chapter 4, eds D. Laskowitz and G. Grant (Boca Raton, FL: CRC Press; Taylor and Francis Group). p. 1-25.

4. Shlosberg, D., Benifla, M., Kaufer, D., and Friedman, A. 2010. Blood-brain barrier breakdown as a therapeutic target in traumatic brain injury. Nat. Rev. Neurol. 6:393-403. doi: 10.1038/nrneurol.2010.74

5. Henemann, U., Kaufer, D., and Friedman, A. 2012. Blood-brain barrier dysfunction, TGF $\beta$ signaling, and astrocyte dysfunction in epilepsy. Glia 60:1251-7. doi: 10.1002/glia.22311

6. Alvarez, J. I., Katayama, T., and Prat, A. 2013. Glial influence on the blood brain barrier. Glia 61:1939-58. doi: 10.1002/glia.22575

7. Cacheaux, L. P., Ivens, S., David, Y., Lakhter, A. J., Bar-Klein, G., Shapira, M., et al. 2009. Transcriptome profiling reveals TGF-beta signaling involvement in epileptogenesis. J. Neurosci. 29:8927-35. doi: 10.1523/jneurosci.0430-09.2009

SUBMITTED: 21 March 2018; ACCEPTED: 27 January 2020;

PUBLISHED ONLINE: 20 February 2020.

EDITED BY: Michael A. Yassa, University of California, Irvine, United States

CITATION: Lin JM, Senatorov VV Jr and Kaufer D (2020) As We Age, The "Shield" That Protects the Brain Gets Leaky. Front. Young Minds 8:10. doi: 10.3389/frym. 2020.00010 
CONFLICT OF INTEREST: VS and DK declare a financial interest in the work described in this manuscript.

The remaining author declares that the research was conducted in the absence of any commercial or financial relationships that could be construed as a potential conflict of interest.

COPYRIGHT () 2020 Lin, Senatorov, and Kaufer. This is an open-access article distributed under the terms of the Creative Commons Attribution License (CC BY). The use, distribution or reproduction in other forums is permitted, provided the original author(s) and the copyright owner(s) are credited and that the original publication in this journal is cited, in accordance with accepted academic practice. No use, distribution or reproduction is permitted which does not comply with these terms.

\section{YOUNG REVIEWERS}

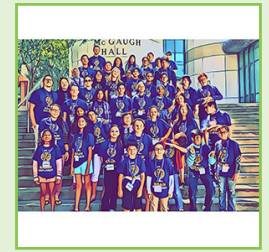

\section{UC IRVINE BRAIN EXPLORER ACADEMY, AGES: 7-14}

We are Brain Explorers from the University of California, Irvine Brain Explorer Academy! We spend our Saturday mornings learning about the brain from scientists at the Center for the Neurobiology of Learning and Memory. We love reading and reviewing Frontiers for Young Minds articles!

\section{AUTHORS}
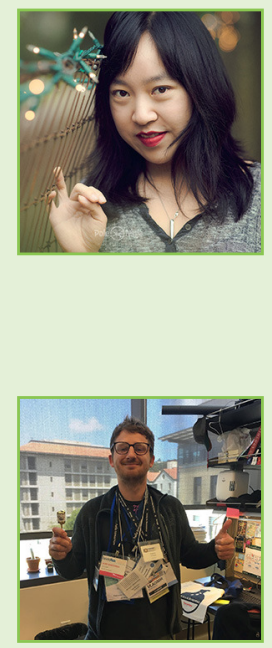

\section{JESSICA M. LIN}

Jessica Lin is a post-baccalaureate researcher in Daniela Kaufer's lab at UC Berkeley. She studies how aging affects the blood-brain barrier and whether blood-brain barrier deterioration has an impact on other age-related diseases, such as Alzheimer's. She hopes to pursue a Ph.D. in the near future. In her free time, she enjoys writing, dancing, and hanging out with her one lizard, three rats, and one pet cat.

\section{VLADIMIR V. SENATOROV JR.}

Vladimir Senatorov graduated with a Ph.D. in Neuroscience from UC Berkeley in 2018.

\section{DANIELA KAUFER}

Daniela Kaufer is a Professor of Integrative Biology and Neuroscience at UC Berkeley. She grew up in Israel, where she received her Ph.D. in molecular neuroscience from The Hebrew University. She moved to California and was a Post-doctoral Fellow at Stanford University. Her lab studies how does the brain deal with perturbations like stress and brain injury and what are the mechanisms underlying trajectories of resilience and vulnerability throughout the life span. Outside of the lab, she enjoys hiking and camping with her family, yoga, and cooking. *danielak@berkeley.edu 